\title{
COMUNICACÕES
}

\section{Extratos aquosos de Annona spp. e Croton heliotropiifolius sobre Scutellonema bradys e prospecção química dos compostos}

\author{
Rosangela da Silva $\operatorname{Lima}^{1} \oplus$, Maria de Fatima Silva Muniz ${ }^{1} \oplus$, João Gomes da Costa $^{2} \oplus$, Kelly Barbosa da Silva ${ }^{3} \bullet$, \\ Alexandre Behling ${ }^{1}[0$
}

${ }^{1}$ Universidade Federal de Alagoas, Centro de Ciências Agrárias, CEP 57100-000, Rio Largo, AL, Brasil; ${ }^{2}$ Embrapa Tabuleiros Costeiros, $57100-000$ Rio Largo, AL, Brasil; ${ }^{3}$ Universidade Federal de Alagoas, Laboratório de Pesquisa de Recursos Naturais, CEP 57072-900, Maceió, AL, Brasil. Autor para correspondência: Maria de Fatima Silva Muniz (mf.muniz@uol.com.br)

Data de chegada: 15/05/2017. Aceito para publicação em: 29/04/2018.

$10.1590 / 0100-5405 / 179913$

Uma alternativa de controle de fitonematoides é a utilização de extratos vegetais. Croton spp. e Annona spp. se destacam pelos tipos de metabólidos secundários $(3,7)$. O trabalho teve por objetivos avaliar o efeito nematicida in vitro dos extratos aquosos de folhas e caule de velame ( $C$. heliotropiifolius Kunth.); de folhas e casca do caule de soncoya (A. purpurea Moc. \& Sesse); e de folhas de araticum-do-brejo (A. glabra L.), de pinha (A. squamosa L.) e de biribá (A. mucosa Jacq.) sobre Scutellonema bradys (Steiner \& LeHew) Andrássy e identificar os compostos secundários nesses extratos.
A coleta de $C$. heliotropiifolius foi realizada em Arapiraca, AL, e uma amostra foi depositada no MAC Herbário do Instituto do Meio Ambiente de Alagoas ( $\mathrm{n}^{\circ}$ 54392); as anonáceas foram colhidas no CECA/UFAL. Os extratos foram obtidos conforme Ferris \& Zeng (4). Em cavidades de placas de Kline foram colocados $200 \mu \mathrm{L}$ do extrato e 20 nematoides juvenis e adultos, extraídos de rizóforos de Dioscorea sp. Água destilada foi usada como controle. Três experimentos foram conduzidos em delineamento inteiramente casualizado, e em cinco repetições sendo a parcela formada por uma cavidade da placa. $\mathrm{O}$

Tabela 1. Imobilidade e mortalidade de espécimes de Scutellonema bradys após 24 horas de exposição a extratos aquosos obtidos de folhas de cinco espécies vegetais, seguido de incubação em água.

\begin{tabular}{|c|c|c|}
\hline Extratos & Imobilidade (\%) & Mortalidade (\%) \\
\hline Biriba & $64,40 \mathrm{c}$ & $23,24 \mathrm{c}$ \\
\hline Araticum-do-brejo & $68,84 \mathrm{cb}$ & $66,04 \mathrm{a}$ \\
\hline Velame & 79,80 a & $60,36 \mathrm{a}$ \\
\hline Pinha & $79,80 \mathrm{a}$ & $40,68 \mathrm{~b}$ \\
\hline \multicolumn{3}{|c|}{ Extratos oriundos de folhas } \\
\hline \multirow[t]{3}{*}{ Imobilidade } & Velame: $y=-0,0227 x^{2}+3,0783 x+11,171$ & 0,8628 \\
\hline & Araticum-do-brejo: $y=-0,0161 x^{2}+2,4749 x+5,3543$ & 0,9605 \\
\hline & Soncoya: $y=-0,0212 x^{2}+2,9802 x+7,7771$ & 0,9290 \\
\hline \multirow{4}{*}{ Mortalidade } & Araticum-do-brejo: $y=-0,0138 x^{2}+2,2509 x+5,3543$ & 0,9581 \\
\hline & Soncoya: $y=-0,0152 x^{2}+2,4038 x+4,3429$ & 0,9722 \\
\hline & Biribá: $y=-0,0064 x^{2}+0,8399 x+5,3314$ & 0,9774 \\
\hline & Pinha: $y=-0,0094 x^{2}+1,5096 x+0,6$ & 0,9938 \\
\hline \multicolumn{3}{|c|}{ Extrato obtido de casca do caule de soncoya } \\
\hline Imobilidade & $y=-0,0131 x^{2}+2,4368 x-9,28$ & 0,8952 \\
\hline Mortalidade & $y=1,0368 x+0,52$ & 0,9203 \\
\hline
\end{tabular}

Médias seguidas de letras iguais, nas colunas, não diferem entre si pelo teste de Tukey, a $5 \%$ de probabilidade. 
primeiro consisitiu de um fatorial 5 x 5 (cinco espécies vegetais e cinco concentrações: $0,25 \%, 50 \%, 75 \%$ e $100 \%$ ), no componente folha. O segundo, caule de $C$. heliotropiifolius, e o terceiro, casca do caule de $A$. purpurea, nas mesmas concentrações. Após 24 horas, foi feita a contagem dos nematoides imobilizados em microscópio de objetiva invertida. Espécimes imóveis foram transferidos para água destilada, considerado-se mortos os nematoides que não recuperaram o movimento após 24 horas. Apenas os dados dos experimentos $1 \mathrm{e}$ 3 foram submetidos à análise de variância, uma vez que no segundo ensaio, os valores para as duas variáveis aleatórias foram iguais a zero. Foram aplicados o teste de Tukey $(\mathrm{P}<0,05)$ e análise de regressão. A prospecção fitoquímica foi efetuada conforme Matos \& Matos (6).

Observou-se significância quanto à imobilidade e mortalidade de S. bradys (Tabela 1). A prospecção química demonstrou a presença de taninos flobafênicos (exceto em caule de C. heliotropiifolius); flavonas, flavonóis e xantonas (exceto em A. purpurea); flavononois (apenas em A. purpurea); catequinas (exceto em caule de C. heliotropiifolius); flavononas (apenas em $A$. purpurea); triterpenoides (apenas em folha de $A$. mucosa) e saponinas (em todos os materiais testados). Segundo Hoste et al. (5) o efeito anti-helmíntico de taninos pode ser atribuído à sua capacidade de ligação com proteínas da cutícula do nematoide, alterando suas propriedades física e química. Atividade anti-helmíntica já foi comprovada em flavonoides e flavonas $(1,8)$ e em triterpenoides e seus derivados (2).

\section{REFERÊNCIAS}

1. Ayers, S.; Zink, D.L.; Mohn, K.; Powell, J.S.; Brown, C.M.; Murphy, T.; Brand, R.; Pretorius, S.; Stevenson, D.; Thompson, D.; Singh, S.B. Flavones from Struthiola argentea with anthelmintic activity in vitro. Phytochemistry, Nantes, v.69, n.2, p.541-545, 2008.

2. Begum, S.; Ayub, A.; Siddiqui, B.S.; Fayyaz, S.; Kazi, F. Nematicidal triterpenoids from Lantana camara. Chemistry \& Biodiversity, Zurich, v.12, n.9, p.1435-1442, 2015.

3. Camurça-Vasconcelos, A.L.F.; Bevilaqua, C.M.L.; Morais, S.M.; Maciel, M.V.; Costa, C.T.C.; Macedo, I.T.F.; Oliveira, L.M.B.; Braga, R.R.; Silva, R.A.; Vieira, L.S. Anthelmintic activity of Croton zehntneri and Lippia sidoides essential oils. Veterinary Parasitology, Amsterdam, v.148, n.3/4, p.288-294, 2007.

4. Ferris, H.; Zheng, L. Plant sources of Chinese herbal remedies: effects on Pratylenchus vulnus and Meloidogyne javanica. Journal of Nematology, Lawrence, v.31, n.3, p.241-63, 1999.

5. Hoste, H.; Jackson, F.; Athanasiadou, S.; Thamsborg, S.M.; Hoskin, S.O. The effects of tannin-rich plants on parasitic nematodes in ruminants. Trends in Parasitology, Cambridge, v.22, p.253-261, 2006.

6. Matos, J.M.D.; Matos, M.E.O. Farmacognosia: curso teórico - prático. Fortaleza: Edições UFC, 1989. 245p.

7. Santos, L.A.R.; Pimenta, L.P.S.; Boaventura, M.A.D. Acetogeninas de anonáceas bioativas isoladas das sementes de Annona cornifolia A. St. Hil. Revista Brasileira de Plantas Medicinais, Botucatu, v.9, n.3, p.48-51, 2007.

8. Silva, V.C.; Carvalho, M.G.; Borba, H.R.; Silva, S.L.C. Atividade anti-helmíntica dos flavonoides isolados das raízes de Andira anthelmia (Leguminosae). Revista Brasileira de Farmacognosia, Curitiba, v.18, n.4, p.573-576, 2008 